\title{
Disputas en torno a la Reforma. Maximio Victoria y las reacciones contra la Facultad de Ciencias Económicas y Educacionales de Paraná (1918-1931) ${ }^{1}$
}

\section{Disputes around the University Reform. Maximio Victoria and the reactions against the Faculty of Economic and Educational Sciences of Paraná (1918-1931)}

\author{
Nicolás Motura \\ Universidad Nacional del Litoral \\ Instituto de Humanidades y Ciencias Sociales del Litoral \\ Consejo Nacional de Investigaciones Científicas y Técnicas \\ nicomotura@gmail.com \\ (Argentina) \\ Osvaldo Vartorelli \\ Universidad Nacional de Entre Ríos \\ osvaldovartorelli@hotmail.com \\ (Argentina)
}

\section{Resumen}

En el presente artículo nos proponemos dar cuenta de los avatares de la experiencia reformista en la provincia de Entre Ríos, con la instalación de la Facultad de Ciencias Económicas y Educacionales de la ciudad de Paraná entre 1918-1931. Para ello haremos foco en la actuación y discursos del profesor Maximio Victoria, un reconocido anti-reformista y opositor a la facultad. La historiografía clásica sobre el tema, ha prestado escasa atención a la recepción de la Reforma Universitaria por fuera de los principales epicentros urbanos. En este sentido, el trabajo ofrece una instancia de exploración.

Palabras Clave: Reforma Universitaria, Maximio Victoria, Paraná, educación.

1. Una versión previa de este trabajo fue presentada en las Jornadas Académicas $A 100$ años de la Reforma Universitaria, desarrolladas en la Universidad Nacional de Rosario durante los días 13, 14 y 15 de junio del 2018. 


\begin{abstract}
In this article we propose to account for the vicissitudes of the reformist experience in the province of Entre Ríos, with the creation of the Faculty of Economic and Educational Sciences of the city of Paraná, between 1918 and 1931. For this purpose, we will focus on the actions and speeches given by Professor Maximio Victoria, a renowned anti-reformist and opponent to the faculty. The classic historiography on the subject has paid little attention to the reception of the University Reform outside the main urban epicenters. In this sense, this work offers an instance of exploration.
\end{abstract}

Keywords: University Reform, Maximio Victoria, Paraná, education.

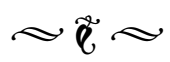

\section{Introducción}

El movimiento reformista nació como una respuesta a un momento político y social específico en el mundo occidental: el de las oligarquías liberal-conservadoras, en pleno proceso de expansión e integración económica mundial (1880-1890). Su impacto tuvo consecuencias internacionales, incidiendo en el mundo de las ideas y aun en el período de entreguerras. Sin embargo, en el caso argentino, son escasos los conocimientos sobre sus alcances fuera de la órbita de las grandes urbes (Buenos Aires, La Plata, Córdoba y Santa Fe). Un caso particular -y escasamente trabajado- es la provincia de Entre Ríos. ${ }^{2}$

Como ha señalado recientemente Ana Clarisa Agüero (2018) algo que caracteriza al proceso de la Reforma Universitaria es la diversidad de actores y experiencias que provocó, lo que

2. Como excepción cabe mencionar los trabajos del equipo de Enrique Ossanna en relación a la historia de la Facultad de Ciencias de la Educación, desde sus orígenes hasta 1973 (Ossanna y López, 2010). No obstante, el rol de figuras como la del profesor Maximio Victoria, no fueron abordadas en profundidad. hace imposible hablar de ella como algo homogéneo y unívoco. Una de las reacciones fue la marcada oposición de algunos actores a los cambios y sus efectos, no sólo en las grandes ciudades, sino también en espacios periféricos como el entrerriano.

En el presente artículo analizaremos las repercusiones que el movimiento del reformismo universitario de 1918 tuvo en la ciudad de $\mathrm{Pa}$ raná, sede de la Escuela Normal de maestros y de la Facultad de Ciencias Económicas y Educacionales de la Universidad Nacional del Litoral. Para ello, observaremos la actuación del profesor Maximio Victoria, director de la Escuela Normal en 1918 e interventor de la Facultad en 1931.

Este actor se destacó por ser un ferviente normalista, católico, opositor a la Reforma, promotor de la "jerarquización" universitaria para finalmente ser el artífice del cierre de la Facultad. Estudiar con detenimiento cómo se desenvuelve será el lente que nos permitirá explicar las reacciones que provocó la Reforma en una ciudad del interior del país. 


\section{La tradición normalista en la ciudad de Paraná}

Por normalismo se entiende al movimiento pedagógico que prosperó en el país desde 1870 hasta mediados del siglo XX. Consistía en una actitud activa del Estado de alfabetizar a la población, que hacia finales del siglo XIX tenía elevadas tasas de analfabetismo y por tanto carecía de los conocimientos básicos y prácticas sociales de la "civilización". Toma su nombre de la primera institución Normal que se instaló en Paraná ${ }^{3}$ y que adapta las ideas positivistas a los métodos de enseñanza aprendizaje (Puiggrós, 2001).

Lejos de ser una tradición homogénea, el normalismo supo combinar características culturales locales y, a veces, contradictorias para hacer pie en los distintos contextos en los que se emplazaban las instituciones. Si bien todas las escuelas se reconocían herederas de este proyecto, diferían en el modo en el que lo llevaban adelante. ${ }^{4}$ Conductista en su manera de aplicar los métodos de enseñanza, el maestro normal se convirtió en el arquetipo de la "civilización" en la lucha contra la "barbarie", 5 así como portador del saber científico legitimado (Herrero,

3. Es importante señalar que la provincia de Entre Ríos y la ciudad de Paraná en particular fueron escenario de la primera institución de formación docente y enseñanza superior nacional, al margen de las universidades nacionales (Córdoba y Buenos Aires) existentes hasta principios del siglo XX. A su vez, la provincia de Entre Ríos contaba con instituciones educativas pioneras y de renombre (por ejemplo, el Colegio Histórico de Concepción del Uruguay) y un sistema educativo que abarcaba todos los niveles. (Salvadores, 1966).

4. Sobre la diversidad de las experiencias del normalismo argentino: Tedesco (1986), Puiggrós (2001), Lionetti (2005), Fiorucci (2014).

5.Para la antinomia civilización/ barbarie ver: Altamirano y Sarlo (1983), Svampa (1994) y Terán (2008).
2014). Maximio Victoria (1912a) fue uno de sus exponentes:

Piénsese que las Escuelas Normales no reclaman reformas radicales para conseguir su estabilidad: fueron organismos de crecimiento natural que han realizado su proceso llenando necesidades apremiantes en la cultura argentina y que reclaman, para su mismo desarrollo, formas científicas en su disciplina, organización y dirección; formas estables y progresivas, no formas regresivas $\mathrm{y}$ anárquicas (p.113).

Institución laica, la Escuela Normal del Paraná poco a poco fue asimilando elementos locales, de impronta católica con aquellos provenientes del laicismo anglosajón. Sus autoridades fueron un ejemplo claro de hibridez ideológica. Entre 1870 y 1876, su director, Jorge Stearns, buscó aplicar las técnicas provenientes de Norteamérica, encabezando una propuesta que no hizo pie en la ciudad por múltiples razones. En primer lugar, por las carencias materiales y humanas. Eran tiempos de revueltas políticas, en las que los hombres y los recursos estaban al servicio de la guerra civil entrerriana ${ }^{6}$ (Schmit, 2015). Y, en segundo término, por la injerencia de la Iglesia Católica que obstaculizaba cualquier intento de enseñanza laica en la ciudad. Se llegó inclusive a impartir enseñanza religiosa a contraturno (Figueroa, 1934, p. 57).

Por eso la gestión del español José María Torres contó con el beneplácito del obispado una vez que Stearns dejó la dirección. Reorganizador

6. Por aquellos días, las revueltas de Ricardo López Jordán (1870-1876), asesino del caudillo Urquiza, captaron toda la atención política y los recursos del erario provincial. Si bien la escuela era iniciativa nacional, la intervención federal y el drenaje de recursos hacia la Guardia Nacional, dejó en segundo plano la experiencia normalista. 
de la escuela, Torres se abocó a subsanar las carencias materiales de la institución, obteniendo los fondos necesarios para su sostenimiento (Salvadores, 1966, p. 150). Para ello reformó los planes de estudio, adecuándolos al entorno. Instauró el orden y la disciplina ${ }^{7}$ con un fuerte componente patriótico y religioso (Kummer, Olalla, Baffico, López, 2010 p. 50). Este viraje, fue continuado por Gustavo Ferrari y Alejandro Carbó (1885-1892) así como por Leopoldo Herrera (1893-1906) y Maximio Victoria (1907-1920), directores posteriores.

De origen tucumano, Maximio Victoria nació el 2 de diciembre de 1871 en la localidad de Villa Granaderos. Estudió en la escuela Normal de Tucumán y por una beca del Estado nacional, se trasladó a Paraná para continuar sus estudios de profesorado durante la gestión de José María Torres (1876-1895). Entre 1898 y 1904 fue inspector de Educación de Santiago del Estero y Corrientes, y ejerció cargos de educación en Catamarca, Buenos Aires y Santa Fe. Retornó en 1907 a Paraná, cuando le ofrecieron la dirección de la Escuela Normal.

Positivista por convicción, Maximio Victoria representó el ala más ortodoxa del pensamiento normalista. Sus principales trabajos versaron sobre la gestión educativa, la pedagogía y el normalismo, ${ }^{8}$ tradición fuertemente im-

7. El normalismo elaboró modelos dirigidos a ordenar, reprimir, expulsar o promover en la escuela aquello considerado "distinto" dentro del canon racial promovido por el Estado nacional. El docente era un apóstol cuya misión era "evangelizar a los bárbaros" El método, la organización escolar, la planificación, la evaluación y la disciplina eran las nociones que organizaban su práctica. Por eso las obras de los pedagogos normalistas versaban en técnicas de cómo materializar "el orden y la disciplina". En Kummer et al. (2010).

8.Entre sus obras se cuentan Victoria $\left(1910,1912,1912^{\text {a }}\right.$ y 1922a ${ }^{\text {a }}$ 1922b, 1936).

90 plementada en su mandato y que fue reacio a modificar. Esta condición lo llevó a enfrentar duramente a las expresiones de la Reforma Universitaria:

Pero es que el organismo educacional mismo sufre desde hace algunos años una crisis de una anarquía sin ejemplo. Recorred los claustros universitarios, vosotros que habéis aprendido sin prejuicio ni maestro, y allí entre la teología abstrusa de su pretendida ciencia social, oiréis las más flagrantes contradicciones entre principio y principio (Victoria, 1912b, p. 253).

\section{Los antecedentes locales}

Durante la primera década del siglo XX, una serie de cambios políticos y sociales, habían alterado sustancialmente el clima de la provincia y la región. En 1912, producto de la aplicación de la ley 8871, la provincia de Santa Fe cambió de signo político con la victoria del radical Manuel Menchaca. Del mismo modo, dos años después, Entre Ríos hizo lo propio consagrando la fórmula radical de Miguel Laurencena y Luis L. Etchevehere.

La Iglesia Católica, referente indiscutida de la educación en todos sus niveles, prontamente entró en conflicto con el gobierno de orientación liberal- reformista. Un ejemplo de ello, fue el conflicto suscitado en 1915 entre el obispado de Paraná, representado en la figura de Abel Bazán y Bustos, y los docentes y estudiantes de la Escuela Normal, apoyados por el gobierno provincial en la figura de Antonio Sagarna. ${ }^{9}$

9. Antonio Sagarna (1874-1949) fue un destacado jurista y político del partido radical entrerriano. Nacido en Nogoyá, egresó como abogado de la Universidad 
El mismo comenzó con una crítica del obispo local, al mitin realizado en defensa del normalismo laico que profesores y alumnos de la Escuela Normal, oficiaron en adhesión a una polémica entre Leopoldo Lugones y Miguel de Unamuno. ${ }^{10}$ En ese encuentro, tanto Victoria como Sagarna, levantaron la defensa de Leopoldo Lugones y dejaron entrever la tensión existente entre catolicismo social y normalismo laico (Carli, 2001, p. 223).

de Buenos Aires y se dedicó a la carrera judicial y a la docencia secundaria en Paraná y Concepción del Uruguay. Miembro de la Corte Suprema provincial, en 1912 decidió afiliarse al radicalismo. Fue elegido diputado nacional en 1913 y ministro de Gobierno desde 1914, cuando el radicalismo ganó las elecciones provinciales. Propició la intervención federal a la Legislatura provincial en 1917, ganándose la antipatía de la Iglesia Católica. Fue embajador en Perú e interventor de la Universidad de Córdoba en 1923. Perteneciente al ala anti personalista, fue designado ministro de Instrucción Pública entre 1923 y 1928, y juez de la Corte Suprema de la Nación en 1928. Es tristemente recordado por ser uno de los autores de la doctrina sobre los gobiernos de facto, aplicada para los golpes de Estado de 1930 y 1943. Fue destituido por el gobierno de Perón en 1947 mediante juicio político. Murió en Buenos Aires en 1949.

10. La controversia se originó por la crítica que el escritor español Miguel de Unamuno le prodigó al normalismo en el diario La Nación y la posterior respuesta que Leopoldo Lugones le realizara. Este intercambio tuvo diferentes repercusiones en los ámbitos normalistas del país, en Paraná, la discusión se tiñó de otras cuestiones referentes a la tensa relación entre el radicalismo provincial y la jerarquía eclesiástica. Ver: Un artículo (15 de junio de 1915). El Diario (ED), p. 2, Archivo Provincial de Entre Ríos (APER), Paraná; Unamuno y Lugones, y el normalismo (16 de junio de 1915), La Acción (LA), p. 1. Biblioteca Provincial de Entre Ríos (BIPER), Paraná; Por la verdad y la justicia (Por Leopoldo Lugones). Moralidad y competencia del Magisterio (17 de junio de 1915), ED, p. 1.
Tildados de "liberales y masones" ${ }^{11}$ los normalistas adherentes fueron atacados por el matutino La Acción, ${ }^{12}$ acusándolos de "cometer actos inmorales". ${ }^{13}$ Se los asoció al socialismo y como parte de un mismo "peligro rojo", llegándolos a vincular con el partido gobernante:

Desde los balcones de la Escuela Normal presenciaban el acto [el mitin] el Director señor Victoria y el profesor ministro doctor Sagarna. Los gritos se sucedían; un grupo se dirigió hacia el Obispado dando mueras a la Iglesia (...) En el trayecto se vivó al partido radical, al socialismo, al liberalismo, a la escuela sin Dios y sin amo; se dieron mueras a los frailes, a la religión católica, a LA ACCIÓN y a su director y al pasar por la casa de éste, los alaridos y los insultos recrudecieron apedreándose las ventanas y las paredes ${ }^{14}$

A pesar de las críticas, los normalistas paranaenses encontraron en este acto una oportunidad de organización que años después pon-

11. De la Escuela sin Dios a la Escuela sin Amo (18 de junio de 1917). $L A$, p. 1.

12.LA fue un diario de extracción católica fundado por Juan Ramón Álvarez Prado en 1913. Al igual que otras publicaciones similares, fue un "arma de combate" contra el liberalismo y la modernidad. Una herramienta que, supuestamente, les permitiría enfrentarlos en su propio terreno (Mauro, 2008, p. 93). Reaccionario desde sus inicios, se opuso terminantemente a las reformas que venían implementando desde 1912 en el país y la provincia. Sus diagnósticos, sombríos y pesimistas, reflejaron las sensaciones de un sector de la intelectualidad local que observaba, estupefacta, los cambios impulsados en el país y los avatares internacionales, como parte de un mismo complot de decadencia y degradación moral.

13. La Dirección de la Escuela Normal y la Acción (19 de junio de 1915). $L A$, p. 2.

14. Bajo el régimen radical. Complot de elementos heterogéneos contra La Acción (23 de junio de 1915). LA, p. 1. 
drían en juego en plena Reforma Universitaria. Entre las novedades se contó con la conformación del primer Centro de Estudiantes de la Escuela. Victoria, paralelamente al accionar de los estudiantes, reaccionó con una carta pública de desagravio ${ }^{15}$ y con un informe dirigido al Consejo General de Educación. Las posiciones en pugna ya comenzaban a perfilarse, como expresan algunos editoriales:

Los exaltados que van vociferando por las calles, apedreando casas e insultando las creencias ajenas son elementos disolventes en el seno de las colectividades, los perturbadores del orden, los enemigos de la paz y de la libertad. La fe está hondamente arraigada en Paraná, es en vano que sus enemigos pretendan arrancarla porque ella forma parte integrante de nuestros hogares, porque ella es el mejor escudo de la tradicional nobleza de esta ciudad. ${ }^{16}$

Acérrimo defensor del normalismo, Victoria vio en este episodio una oportunidad de demostrar a la opinión pública que a pesar de sus creencias personales (cercanas al catolicismo), el magisterio era un sacerdocio laico, muy por encima de cualquier bandería ideológica o política (Victoria, 1922a). Esta concepción de cómo debía conducirse la tarea pedagógica, años después, lo hizo tomar otra postura frente a los estudiantes.

\section{Los ecos de la Reforma Universitaria en Paraná}

Desde principios del siglo $\mathrm{XX}$, se fue gestando una opinión pública que demandaba una inter-

15. La Escuela Normal y La Acción (20 de junio de 1915). ED, p. 1.

16. Dos tendencias (1 de julio de 1915). LA, p. 3.

92 vención más activa por parte del Estado para resolver los problemas de integración social de los sectores medios y bajos. La Reforma Universitaria fue la expresión de un movimiento mucho más amplio de democratización que atendía a la cuestión social. ${ }^{17} \mathrm{~A}$ diferencia de La Plata y Buenos Aires, Córdoba era descrita como un bastión del conservadurismo y la oligarquía eclesiástica. Por eso el estallido se tornó violento allí, donde las contradicciones eran mayores (Ciria y Sanguinetti, 2006). En 1918, la situación era insostenible y la oportunidad política de introducir cambios, trató de ser aprovechada por Hipólito Yrigoyen en el poder.

Ante la lentitud de la administración radical de resolver el conflicto, el 9 de septiembre de 1918, los estudiantes decidieron tomar la universidad, asumiendo plenamente su dirección. Esta situación llevó al gobierno a mandar al ejército para aplacar la rebelión, pero la victoria estaba consumada: el presidente envió al ministro José Salinas y aceptó las renuncias de los docentes más conservadores, cuyos puestos fueron ocupados por los reformistas. Los nuevos estatutos establecían los dos grandes principios de la reforma: la docencia libre y el cogobierno universitario (Buchbinder, 2009).

El día 19 de junio, llegaron las noticias de Córdoba. Al día siguiente, el Centro de Estudiantes del Colegio Nacional tomó la iniciativa e invitó a los centros del Colegio Histórico de Concepción del Uruguay y de la Escuela Normal del Paraná, a sumarse a la huelga en solidaridad con sus pares cordobeses. ${ }^{18}$ Luego de reuniones en la Biblioteca Popular de Paraná, el día sábado 22, los estudiantes decidieron

17. Véase Zimmerman (1994) y Suriano (2000).

18. El mitin del sábado (22 de junio de 1918). ED, p. 1. 
medidas de fuerza y convocaron a un mitin para el domingo 23. Las adhesiones al encuentro fueron muy variadas, desde organizaciones gremiales y de la sociedad civil. ${ }^{19}$ Entre las mismas se destacaron el Ateneo Popular, el Centro de Reformas Sociales, el Círculo de Profesores de Paraná y la Seccional local de Telegrafistas y Empleados Postales. ${ }^{20}$

En el mitin realizado en la plaza $1^{\circ}$ de Mayo, y que fue custodiado por la policía provincial, ${ }^{21}$ los estudiantes declararon la conformación de la Federación de Estudiantes de Paraná y declararon huelga de tres días, sin asistencia a clases. $^{22}$

Las reacciones del director de la Escuela Normal, profesor Maximio Victoria -quien años antes había promovido el accionar estudiantilesta vez fueron distintas: suspendió por cinco días a los huelguistas, bajo acusación de incitación y uso de la violencia, y lanzó duras críticas a los móviles de la huelga: ${ }^{23}$

Desiertas están las aulas. Más desiertas aún están vuestras rebeldías de conceptos y de aspiraciones cívicas. Esta ciudad, que tanto

19. La movilización se articulaba en una más regional, que enlazaba a estas instituciones paranaenses con la Federación de Asociaciones culturales y el Comité Pro Universidad, actuante en las ciudades santafesinas de Santa Fe y Rosario. Véase Bacolla (2018).

20. El movimiento liberal estudiantil. Otras adhesiones (22 de junio de 1918). ED, p. 4.

21. La huelga de estudiantes y el gobierno provincial (21 de junio de 1918). ED, p. 1.

22. El movimiento liberal estudiantil. Manifestación del domingo (25 de junio de 1918). ED, p. 1.

23. Esta actitud de rechazo de la huelga estudiantil, también se relacionan con la postura en Santa Fe de la Unión Universitaria, los alumnos del Colegio de la Inmaculada Concepción, el Centro de Estudiantes Católicos. Véase Bacolla (2018). estudia, no ha escuchado de vuestros labios sino vivas a la holganza, a una vaga solidaridad de gremio y a un liberalismo vacío. (...) ¡Ea! ¡Jóvenes! Si queréis vivir para la libertad, volved viril y voluntariamente a las disciplinas escolares. La República necesita remover sus viejas instituciones, pero con un evangelio que radica en el estudio y en el aprendizaje continuo y fuerte, no en la fácil holgazanería. (...) La irrupción de violencias juveniles inocuas, no tiene ningún significado espiritual: ni siquiera tonifica como el aire matinal, ni derrumba sus muros inclinados como hace el huracán. ${ }^{24}$

El ministro de gobierno provincial, Antonio Sagarna, se hizo eco y le respondió a Victoria, refutando sus principales argumentos. $\mathrm{Su}$ visión era la de un gobierno provincial que simpatizaba con la protesta de los estudiantes y pretendía sacar provecho de ella, por lo que en esta ocasión se encontraban en veredas opuestas:

No hay tal vacuo desierto en el reclamo estudiantil. No han de venir ellos a una disertación académica sobre rumbos universitarios (...) Con más intuición por frescura y sanidad de almas que sabihondura, los escolares de Paraná proclaman su solidaridad integral con las sustancias causales del movimiento cordobés: la urgente necesidad de airear las aulas de una casa de estudios, cuyas mentes y usufructos "aspiran para la humanidad a la actitud de estatua de piedra, inmóvil a orillas del río del tiempo. ${ }^{25}$

No obstante, no todas las voces del radicalismo entrerriano simpatizaban con la causa cordo-

24. La Dirección de la Escuela Normal. Un manifiesto a los estudiantes (25 de junio de 1918). ED, p. 2.

25. Una carta del Dr. Antonio Sagarna sobre el manifiesto del Director de la Escuela Normal (27 de junio de 1918). ED, p. 5. 
besa, lo que era un síntoma de las discrepancias existentes en el elenco gobernante y que se traducirán en la década de 1920 en el enfrentamiento entre personalistas y anti- personalistas. Leopoldo Melo, ${ }^{26}$ quien entonces era un prominente radical anti yrigoyenista, decía lo siguiente: "El conflicto cordobés debe observarse con cuidado, pues puede existir entre las causas que lo generan, otros motivos que no sean precisamente universitarios". ${ }^{27}$

Por su parte, Victoria respondió a las críticas de su colega con otra carta que adquirió público conocimiento, reafirmando su postura anti-reformista:

El negativismo de la juventud es el fácil aleteo del pichón que, por picar, no vuela ni pica. $Y$ atribuyo al actual auge del sectarismo y retrogradación religiosa del país, precisamente a que las grandes corrientes liberales son el juguete obligado de espíritus en formación. Evidentemente, lo que para Ud. es detalle y corolario, la formación del profesor, en su carácter, en sus conceptos, en su conducta y hasta en el pequeño repliegue de su alma, es para mí, el teorema, el nexo de la cuestión. (...) Creo, por ejemplo, cosa muy grave para el país, que un maestro ar-

26.Leopoldo Melo (1869-1951) fue un importante dirigente de la UCR y lideró la oposición a Hipólito Yrigoyen, llamada antipersonalismo. Fue diputado nacional, dos veces senador por Entre Ríos y presidente provisional de Senado en representación del radicalismo. En 1924 formó la Unión Cívica Radical Antipersonalista y fue candidato a presidente de la Nación por dicho partido en 1928, siendo derrotado por el propio Yrigoyen. En 1931 apoyó la candidatura de Agustín P. Justo y se sumó a la Concordancia con la Unión Cívica Radical Antipersonalista siendo designado Ministro del Interior.

27. La opinión del Dr. Leopoldo Melo (21 de junio de 1918). $L A$, p. 3.

94 gentino vista sotana o cargue la bandera roja del anarquismo. ${ }^{28}$

La excusa de la extorsión de los huelguistas a sus compañeros, a quienes acusaban de "carneros", fue el motivo más fuerte esgrimido por Victoria. No obstante, y ante la airada respuesta de altos funcionarios provinciales, se levantaron las sanciones y se calmaron las aguas al interior de los claustros. Pero esta situación no duraría mucho tiempo.

Desde 1917, la irrupción del socialismo soviético fue interpretada como una perversión al orden, una confrontación directa a las tradiciones e ideales defendidos por los normalistas. El discurso que atravesaba el momento maximalista estaba imbuido de una inminente sensación de final, pero también contenía un tópico propio del fin de siècle: la degeneración o decadencia. ${ }^{29}$ En esta clave fue leída la Reforma Universitaria. Referentes como Victoria entendían que era un subproducto de una crisis de valores más generalizada:

Por esta razón no vacilo en calificar de peligrosa para las conquistas hechas, ese contagio por la novedad sovietista, que pone ideas viejas y perturbadoras, en países e instituciones nuevas, que se desenvuelven dentro de modalidades propias y que nada ganan con el cambio, sino en la desorientación de

28. Respuesta del Director de la Escuela Normal a la carta del Dr. Sagarna (28 de junio de 1918). ED, p. 1.

29. Como ha demostrado Reinhart Koselleck (2012), el concepto de "decadencia" no está separado de su pareja conceptual, el concepto de "progreso", sino que ambos mantienen una relación de complementariedad. Una posición similar es la de Pierre Chaunu (1983). Otros análisis se pueden encontrar en Burrow (2001) y en Herman (1998). Mariela Rubinzal (2017) ha llamado la atención sobre la construcción y circulación de discursos decadentistas en los tiempos del maximalismo. 
los sabios principios que informan su organización (Victoria, 1922b, p. 48).

Los jóvenes se auto percibieron como agentes que venían a regenerar los vicios de las instituciones "criollas". Criticaban el utilitarismo en la universidad; los profesionales eran poco versátiles y, a su vez, poco comprometidos con su entorno social (Buchbinder, 2006). Pero con el transcurrir de los meses, esa mirada optimista fue mutando a otra de decepción y pesimismo. A medida que la política impregnaba los claustros, el desencanto con cualquier protesta estudiantil, se emparentó con la crítica a cualquier huelga obrera (Tato, 2004). Los acontecimientos de la Semana Trágica de enero de 1919 significaron un punto de inflexión en la percepción del "momento maximalista", en especial desde el arco del radicalismo. El miedo comenzó a operar como constituyente esencial de la vida cotidiana y de la acción (o la inacción) política. ${ }^{30} \mathrm{Y}$ los universitarios eran presa fácil de "falsos profetas": "En la barahúnda de semisabios y principalmente entre maestros, bachilleres y profesores de Universidad, lectores inteligentes de la biblioteca blanca y de la roja, es donde se reclutan los más decididos adeptos y guiadores del socialismo" (Victoria, 1922b, p. 43).

\section{Maximio Victoria y la nueva facultad}

Producto de la creación de la Universidad $\mathrm{Na}-$ cional del Litoral en 1919, la ciudad de Paraná se constituyó en sede de la flamante Facultad de Ciencias Económicas y Educacionales que comenzó a organizarse y funcionar a mediados

30. Para ampliar la temática: Lvovich (2003), Tato (2004), Echeverría (2009) y McGee Deutsch (2003). de 1920 (Zanini, 1926, p. 139). ${ }^{31}$ La tradición pedagógica local, fue un factor determinante para su instalación, por lo que la Escuela Normal pasaba a ser, no solo el edificio donde la albergaría, sino también la piedra angular de su constitución (Piazzesi y Bacolla, 2015).

La Universidad después de una década de intentos de conformarla se materializó con el apoyo yrigoyenista, ${ }^{32}$ pero en la provincia de Entre Ríos gobernaba desde 1922 un radicalismo opositor a su figura. ${ }^{33}$ La carestía de recursos, producto de las pujas internas entre personalistas y anti-personalistas, comenzó a enrarecer el clima entre los miembros de la comunidad universitaria.

Victoria, junto a otros normalistas, reconociendo la inevitabilidad del emplazamiento, vieron la posibilidad de "jerarquizar" la escuela $\mathrm{y}$ contribuyeron a promover la facultad. Como

31. Entre las carreras ofrecidas por la facultad se incluían el doctorado en Filosofía y Letras, Profesor de Enseñanza Universitaria y Profesor de Enseñanza Secundaria, Normal y Especial con orientaciones en Filosofía y Pedagogía, Letras, Historia y Geografía; Matemáticas, Química y Mineralogía; Física; Ciencias Biológicas; Ciencias Económicas; Historia y Geografías Argentinas; Instrucción Moral y Cívica; Ciencias Agrarias; Lenguas Vivas; Trabajo Manual, Dibujo y Matemática elemental. Además continuaba ofreciendo en la Escuela Normal anexa a ésta, la formación de Maestro Normal Nacional.

32. Cabe señalar que la Universidad del Litoral se erige sobre instituciones previas, tanto de Santa Fe, como de Rosario y Paraná. La coyuntura de movilización y el apoyo del gobierno nacional sellaron finalmente el éxito de la propuesta de una universidad regional, proyecto que había recorrido casi una década desde su elaboración en diversas claves y con múltiples y contrapuestos respaldos. Ver Bacolla (2018).

33. El radicalismo entrerriano se caracterizó por cierta renuencia a la figura de Hipólito Yrigoyen. Nos referimos puntualmente a la figura de Ramón Mihura que gobernó entre 1922 y 1926, dentro de la línea anti personalista alvearista. 
reconocimiento a su trayectoria, fue designado director de la Escuela Normal Anexa -sede de las prácticas y del reclutamiento de alumnos- $\mathrm{y}$ titular de la cátedra de Historia de la Educación (Kummer, et al., 2010, p. 102). Sin embargo, su anhelo de crear una institución que imitara a l'École Normal Supérieure francesa pronto chocó con la realidad de la experiencia reformista (Culó, 1949). En la elección del plantel docente, se privilegió a aquellos de extracción "universitaria" por sobre los de origen normalista (Carli, 1995, p. 115).

Al calor del nuevo clima de ideas, la Escuela Normal Anexa fue quedando cada vez más relegada de la nueva facultad. Corrientes pedagógicas como el escolanovismo, ${ }^{34}$ comenzaron a cuestionar los cimientos del normalismo y propiciaban una revisión de los órdenes y métodos de antaño. Tal situación fue convirtiendo a Victoria en portavoz crítico del proceso en marcha, llegando a afirmar:

En un período de complacencias o de crisis, pongamos por caso, degeneró la autoridad moral del maestro; el buen humor del alumno puso al revés su ciencia infusa, la jerarquía y la consideración personal, teologías ancestrales, indignos del progreso quedaron rezagadas; e ipso facto, por quitarse allá esas pajas, la juventud resolvió cambiar

34. El escolanovismo o movimiento de la Escuela Nueva, fue una corriente pedagógica que se desarrolló en las primeras décadas del siglo XX, como respuesta a la pedagogía positivista de raigambre conductista. Concebían que la educación recibida fue un fracaso que derivó en las guerras mundiales y en la crisis de los valores de occidente. A sus defensores los unía la búsqueda de la autonomía de los estudiantes, sin por ello proponer modificaciones estructurales o una democratización sustantiva de la enseñanza. Entre sus principales exponentes podemos mencionar a Olga y Leticia Cossetini, Luis Iglesias, José Rezzano, Celia Ortiz de Montoya, Florencia Fossati, entre otros.

96 su papel de educando por educadora, pues estos maestros según ella, son la regresión misma, aquellos programas son el absurdo en persona y este régimen disciplinario es la inquisición estúpidamente levantada de su tumba (Victoria, 1922b, p. 51).

La juventud, como nuevo actor político que irrumpía en la escena pública, aparecía a los ojos del director de la Escuela Normal Anexa, como el depósito de todos los males de época, en tanto y en cuanto cuestionaba la autoridad pedagógica y las tradiciones existentes. Las intervenciones de la "masa estudiantil" y su participación activa en relación a la nueva facultad, fue interpretada como una forma de degradación de la política. Esta actitud no era exclusiva de Victoria, y diferentes espacios editoriales, al igual que otras figuras destacadas también captaron este momento de crisis generalizada. ${ }^{35}$ En un escrito de aquellos años manifestaba:

La novedad (...) radica, casi exclusivamente, en la intervención del alumnado en el gobierno escolar: y según las voces corrientes de la calle, pues el programa queda embotellado en un virtuoso laconismo, la Reforma consiste en la intervención de la masa estudiantil agremiada y armada, en la confección de estatutos y programas, en la designación de profesores y en todo acto administrativo que implique una orientación directa y eficiente (Victoria, 1922a, p. 52).

Pero sus aspiraciones a ser designado decano de la facultad en el proceso de normalización, moderaron su actitud y lo hicieron permanecer allí. La idea, una vez en su dirección, era imprimirle su impronta al margen de la experiencia

35. Véase Mauro y Zanca (2018) y Moyano (2017). 
universitaria. Sin embargo, fue Antonio Sagarna quien asumió el decanato en 1921.

El enojo y la decepción se apoderaron de Victoria. En su carta de renuncia dirigida a las autoridades de la facultad (como se cita en Kummer et al., 2010), expresaba:

En el Consejo Directivo de la nueva institución no ha sido incluido ni el personal directivo que ha planteado su organización, ni el único profesor de la materia esencialmente profesional que debería servir (...) en una facultad que pretende cultivar la aptitud de los educadores para formar al profesorado secundario de la nación (p. 105).

En este sentido, para mediados de la década de 1920, la opinión de muchos profesores distaba bastante de las expectativas que el movimiento provocó en sus inicios. En parte, porque las promesas de "jerarquización" quedaron inconclusas, pero fundamentalmente, porque había una sensación de que la política partidaria había echado a perder sus buenas intenciones. A la vez, prácticamente ningún docente de la antigua escuela ocupaba espacios de relevancia en la nueva institución.

Entre 1922-1923, el presidente de la Nación, Marcelo T. de Alvear decretó la intervención de la Universidad del Litoral, dando asidero a estas voces desencantadas con la Reforma. La elección del paranaense Pedro Martínez al rectorado junto a Casimiro Olmos al decanato de la facultad, trajo cierta estabilidad al proceso hasta 1927 y logró apaciguar a los descontentos.

No obstante, muchos estudiantes y docentes de la casa, no satisfechos con la injerencia del poder político en los claustros, poco a poco se fueron alejando de los ideales que los movili- zaron. Estas voces eran recogidas en los editoriales de redacción y artículos de la Revista Universitaria, creada por la Asociación Estudiantil Universitaria y en la cual participaban prominentes intelectuales y profesores de la región (Kummer et al., 2010, pp. 96-97). ${ }^{36}$ En un editorial se sostenía la necesidad de recuperar la figura del "apostolado docente" frente al desgaste o decadencia de los maestros, e inclusive la profundización de la selectividad de la carrera docente:

Sea porque el espíritu docente no llegue hasta el corazón de los alumnos, sea porque la época o el ambiente no lo dispongan así, lo cierto es que muy raras veces quienes prometen ser maestros, lo hacen con el dictamen que les indique la ruta o el camino a seguir (...). Estamos en el siglo del metal $y$ todo se coteja en oro. El maestro enseña para vivir cuando debería vivir para enseñar. ${ }^{37}$

A su vez, la creciente desconfianza en el sistema político quedó reflejada en un artículo de Joaquín Castellanos ${ }^{38}$ sobre la crisis del liberalismo argentino. En él se hacía un repaso de

36.Sobre la relación entre las revistas y la Reforma Universitaria podemos destacar a Bustelo (2015).

37. Profesionalismo y pedagogía. A propósito de la escuela santafecina reformada (agosto de 1925). Revista Universitaria. Órgano Oficial de la Asociación Estudiantil Universitaria $(R U)$ 1(2), p. 1. Fondo Histórico de la Escuela Normal (FHEN), Paraná.

38. Joaquín Castellanos (1861-1932) fue un jurista salteño que en su juventud militó con Carlos Tejedor y con posterioridad fue uno de los fundadores de la UCR en el ala alemista. Además de abogado, fue poeta y docente universitario. Dio clases en la Universidad de Buenos Aires, La Plata y en Paraná. Fue gobernador de Salta entre 1919 y 1922, pero su gestión no contó con el visto bueno de Yrigoyen que decidió intervenir la provincia y apartarlo. Desde allí se dedicó a la literatura y la docencia universitaria. En Pereira (2012). 
la situación política de los partidos, la cual era caracterizada como en "estado de descomposición”. El partido radical y el partido socialista eran incapaces de construir una "democracia superior", sucumbiendo, en cambio, a la oligarquía, la demagogia y al "sovietismo", todas "enfermedades de la democracia". ${ }^{39}$ Para el autor los problemas de la democracia, incluso, podían tener una explicación de carácter racial:

La democracia argentina es una realidad histórica, social, política y de entraña psicológica en nuestra existencia colectiva. Pero nuestra democracia nació afectada de males hereditarios cuyo virus se ancestraliza hasta el coloniaje, y más allá, hasta el fondo mismo de nuestras múltiples maternidades raciales..$^{40}$

Los ecos de la Revolución Rusa y el temor al "momento maximalista" en el país se expresaban en una crítica contundente de las acciones llevadas a cabo en la Semana Trágica. En este sentido, Castellanos consideraba que la represión era funcional a los intereses revolucionarios y debía optarse por una justicia "proporcionada", afín a un "socialismo civilizado". ${ }^{41}$ Desde una perspectiva similar, Raúl Villarroel $^{42}$ criticaba la represión ejercida por las

39. Castellanos, J. La crisis del liberalismo argentino (agosto de 1925). RU, p. 17.

40. Castellanos, J. La crisis del liberalismo argentino (agosto de 1925). RU, p. 17.

41. Castellanos, J. La crisis del liberalismo argentino (agosto de 1925). $R U$, p. 18.

42. Raúl Villaroel (1878-1972) fue un abogado y profesor que participó activamente como cronista de la Revista Argentina de Ciencias Politicas (RACP). Pertenecía a la Logia masónica Armonía, institución destacada por intervenir en la vida pública santafecina. En su ciudad también presidía la asociación liberal de Libre Pensamiento, que inicialmente tuvo un acercamiento a la UCR Santa Fe, pero que no logró alianza política 98 clases gobernantes, pero también la violencia revolucionaria: ${ }^{43}$

Por el camino de la violencia y de la fuerza, los pueblos (pues no se trata solo del proletario) serán siempre vencidos por la violencia y la fuerza organizadas (...). Sólo por la vía del estudio y de la ciencia, podrán los pueblos, las multitudes, las masas trabajadoras, librarse y conseguir la igualdad de derechos y de ventajas sociales que hoy sólo se les reconoce en teoría. ${ }^{44}$

Tanto el conservadurismo como el comunismo y el anarquismo eran percibidos como parte de dos extremos perjudiciales para la política. ${ }^{45} \mathrm{En}$ consecuencia, el estancamiento en el pasado de unos y la marcha irrestricta al futuro "utópico" de los otros eran males que explicaban el desmembramiento de las instituciones. ${ }^{46}$ Por su parte, los diferentes artículos de la revista no condenaban a la Reforma Universitaria, pero sostenían su agotamiento y necesidad de relanzamiento:

alguna. Este espacio de sociabilidad reunía a diversos intelectuales locales de raíz liberal, pero de diferentes extracciones políticas, que veían en el radicalismo una oportunidad para materializar sus ideas. Véase: Carrizo (2009) y Bertero, Pini y Vicentín (2015).

43. Estas opiniones también las expresa en $R A C P$, donde ofrece una crónica detallada del conflicto en la Universidad Nacional del Litoral (UNL) entre diversos sectores y sus lecturas del reformismo universitario. Bacolla, (2018).

44. Villaroel, R. (marzo y abril de 1926) Reflexiones filosóficas sobre problemas sociales. RU 1(9), p. 25.

45. En sucesivos artículos, Raúl Villaroel apoyó una visión más liberal del reformismo universitario y una profunda crítica a su costado electoralista. En Piazzesi y Bacolla (2015).

46. Villaroel, R. Reflexiones filosóficas sobre problemas sociales (marzo y abril de 1926). $R U$ vol. 1, n. 9, p. 26. 
El estudiante ha dejado dormir sus ideales y aquel programa substancioso que llegara a traducirse en su breviario, ya no es ni siquiera una promesa. Es un velo fatal, de fatiga, de cuasi inercia que va invadiendo palmo a palmo los corazones, brazos y cerebros. ${ }^{47}$

\section{Los avatares del reformismo. El cierre de la Facultad de Educación}

Producto de un nuevo conflicto no resuelto en la Facultad de Ciencias Médicas de Rosario, el recién electo presidente Yrigoyen decidió, en 1928, intervenir una vez más la Universidad en su conjunto. ${ }^{48}$ Para ello encargó la tarea al médico Roque Anselmo Izzo quien pretendió retrotraer los estatutos universitarios a los días previos a 1923 para volverla "un ejemplo para las universidades argentinas". ${ }^{49} \mathrm{El}$ decano interventor, Luis Juan Guerrero, colaboró activamente con la intervención, cesanteando algunos docentes y designando otros. ${ }^{50}$

Más allá de las críticas, ${ }^{51}$ en 1929, bajo la dirección de Hugo Calzetti, se creó el Instituto

47. ¡Arriba los corazones! (mayo y junio de 1926). $R U$, 1(11), p. 1.

48. El texto del decreto que dispone la intervención de la Universidad del Litoral (9 de noviembre de 1928). ED, p. 3 .

49. El interventor de la Universidad del Litoral aspira a que el alto instituto sea un modelo en su género ( 2 de diciembre de 1918). ED, p. 1.

50. Fueron cesanteados Amelia S. Grosemy, María Inés Álvarez y se obligó a renunciar al profesor Filiberto Reula a la dirección de la Escuela Normal Anexa. Además, fueron nombrados Vicente Fatone, Joaquín Romero, José Imbelloni y se ratificó a los docentes de extracción universitaria. Ver Piazzesi y Bacolla (2015).

51. Nota del rector Rafael Araya al ministro de Justicia e Instrucción pública de la Nación (14 de noviembre). $E D$, p. 4. de Pedagogía, con fuerte impronta escolanovista, llegando inclusive a proponer el cambio de nombre de Escuela Normal, por el de Escuela de Pedagogía. Según sus miembros la escuela debía ser "autárquica en lo económico, autónoma en su gestión, promotora de la educación moral y activa partícipe de la vida estudiantil”. La intención última de estos pedagogos era sustituir el paradigma alfabetizador del normalismo, por uno más filosófico que promoviera un orden cultural diferente para la "nueva juventud" (Carli, 1995, p. 118).

Esta afrenta a la tradición, llevó inclusive a un pedido del Centro Juventud de suprimir la facultad, para volver al clima "cívico y de rectitud" alejado de la política que reinaba en la antigua Escuela Normal. En esos años, poco a poco los estudiantes y docentes comenzaron a alejarse del ideario yrigoyenista, procurando duras críticas a sus intervenciones y abonando el terreno para el golpe: "Puede pues, el señor Yrigoyen continuar abusando de su poder, de la violencia y de la fuerza, que apresurará más rápidamente su caída fatal irremediable". ${ }^{52}$

A mediados de 1930, se iniciaron las gestiones para elegir las nuevas autoridades. El 19 de julio, fue electo el ingeniero José Babini ${ }^{53}$ como

52. La juventud universitaria en contra de la dictadura (8 de noviembre de 1929). ED, p. 1.

53. José Babini (1897 -1984) fue un ingeniero y matemático que profesionalizó la enseñanza de la historia de la ciencia en la Argentina. Fue profesor durante muchos años de la facultad de Química de Santa Fe y de Ciencias de la Educación de Paraná, de las cuales llegó a ser su decano. Tuvo una extensa producción académica nacional e internacional. En 1955 fue designado decano interventor de la facultad de Ciencias Exactas y Naturales de la Universidad de Buenos Aires (UBA). En 1957 fue nombrado organizador y rector interino de la Universidad Nacional del Nordeste (UNNE) y en 1958 director de Cultura del gobierno del presidente Arturo Frondizi. Formó parte del Consejo Nacional de 
decano. Pero la situación política y económica del país conspiraba contra su continuidad, dando asidero a las expresiones más reaccionarias.

\section{Maximio Victoria, delegado interventor}

El golpe de estado del 6 de septiembre de 1930 fue bien recibido por la prensa, ${ }^{54}$ el radicalismo local y por muchos docentes de la Facultad. La experiencia del interventor Izzo (1928-1930) había contribuido a crispar los ánimos de docentes y estudiantes normalistas, ${ }^{55}$ por lo que

Investigaciones Científicas y Técnicas (CONICET) y se convirtió en el primer presidente del directorio de la Editorial Universitaria de Buenos Aires (EUDEBA). Murió a los 87 años recibiendo distinciones de todo tipo por su labor.

54.ED era básicamente una publicación de opinión, más que de información. Promotor de candidaturas, crítico de los opositores y defensor de las propias iniciativas, durante muchos años (desde 1914) se convirtió en la publicación oficial del radicalismo. Desde su surgimiento, se sostuvo por el aporte generoso de sus militantes/ redactores y por un sistema de suscripción, tendiente a llegar al público exclusivamente radical o afín a sus ideas. La inviabilidad económica de una publicación llevó a que en 1919 se constituye una sociedad empresaria con recursos privados. En la década de 1920, ED adoptó un tono más comercial y reemplazó a una parte de sus redactores "militantes" por otros más afines a la nueva situación que comenzaba a transitar la empresa, adaptando sus contenidos al gusto de una ciudadanía cada vez más demandante, consecuencia de la ampliación de los consumos culturales y los mayores niveles de alfabetización (Saítta, 2013). A pesar de ese viraje, en su plantilla de columnistas, se mantuvo a aquellos de extracción radical, dándole al matutino una impronta ideológica particular (Vázquez, 1970).

55. La intervención Izzo planteaba nuevas reglas para la agremiación estudiantil, y la representación de los diversos estamentos en el co gobierno de la UNL, lo que provocó grandes rechazos en la extracción más reticente al yrigoyenismo. Véase: Piazzesi y Bacolla (2015).

100 la "revolución de septiembre" fue vista como oportunidad de revanch ${ }^{56}$ por quienes fueron cesanteados y apartados en el interregno.

Las denuncias por los desmanejos del yrigoyenismo fueron moneda corriente, en un tiempo en que las finanzas locales y nacionales estaban sufriendo los coletazos de la crisis económica internacional:

La intervención a la Universidad, una de las más arbitrarias intervenciones decretadas por Yrigoyen tuvo en esta capital un delegado interventor, que creó sin medida cátedras y cargos, para ubicar a elementos de comité. En la Escuela Normal, por ejemplo, hay empleados que no ejercen función ninguna. ${ }^{57}$

Las carencias presupuestarias, se combinaron con denuncias de fraude y excesos. La necesidad de recortes en tiempos de crisis, reflotó la idea de los normalistas nostálgicos que reclamaban el cierre de la facultad y la vuelta de la Escuela Normal de Profesores. Es por ello que, en enero de 1931, Victoria retornó a la ciudad, como delegado interventor:

Los espíritus se tranquilizan, ahora, con esta perspectiva del restablecimiento definitivo de un instituto erigido sobre uno de los organismos educacionales más prestigiosos del país (...) Políticos y educadores dilentanttis [sic] se enseñorearon de la vieja casa de estudios y de su moderna creación en tren de avasallar todo lo que fuera un título tradicionalista o un derecho legítimamente adquirido en una larga consagración a la docencia (...) Lo demás quedó a cargo

56. Memorial elevado por los profesores de la Facultad local al Consejo Directivo (19 de noviembre de 1930). $E D$, p. 3.

57. Por qué al personal de la Escuela Normal no se le paga desde octubre (24 de diciembre de 1930). ED, p. 2. 
del klan [sic] reformista que al abrigo de las arcas fiscales, vitoreaban al Mesías reparador, inoculando la demagogia universitaria cuyos efectos se están sintiendo en todo el país. ${ }^{58}$

La necesidad de achicar las cuentas llevó a que la Universidad redujera su presupuesto al de 1927, por lo que se propuso la eliminación de las facultades de Química de Santa Fe, de Ciencias Económicas y Educacionales de Paraná y de Agronomía de Corrientes “dado que los gastos no compensan los beneficios que producen". ${ }^{59}$ La Escuela Normal inclusive, limitó el ingreso a sus cursos por "la abundancia de los institutos pedagógicos del país" y "la excesiva producción de maestros". ${ }^{60}$ Las voces contrarias al cierre de la facultad fueron tibias. Pocas asociaciones y particulares ${ }^{61}$ se manifestaron contra su cierre. La prensa local, reflejaba las sensaciones generalizadas:

Todos los factores de la cultura local están comprometidos en la consolidación del instituto cuyos destinos pasan hoy a la más alta autoridad de la instrucción pública del país. La capacidad profesional del interventor, garantiza de antemano el éxito de la empresa exigida por la crisis de la Universidad y por el mandato reparador de un movimiento patriótico cuya influencia no podría de-

58. La situación de la Facultad (11 de enero de 1931). $E D$, p. 1.

59. El presupuesto de la Universidad del Litoral (22 de enero de 1931). ED, p. 2.

60. Limitación del ingreso a la Escuela Normal (24 de enero de 1931). ED, p. 4.

61. Una excepción fue el profesor Joaquín Castellanos que publica una carta abierta solicitando al presidente de facto intervenir en la disputa. Véase En una nota al presidente provisorio el Dr. Joaquín Castellanos se interesa por la suerte de la facultad ( 8 de febrero de 1931). ED, p. 6. tenerse en estas casas de estudios que deben ser el alma misma de la Nación. ${ }^{62}$

Las adhesiones tardaron en llegar, exigiendo "sostener el estatus universitario" ${ }^{63}$ de la casa de estudios. Pero su suerte ya estaba echada. En una memoria de 1936, Victoria (1936) se enorgullece por la tarea realizada:

En Paraná fui docente de su Facultad de Educación y asistí a su nacimiento. Pero provoqué su deceso vergonzante cuando la invadieron sin pudor los filisteos (...) Aunque fuera de jactancia el creer que estoy a mano con mi destino, por lo menos, puedo decir que cierro sin remordimientos $\mathrm{mi} \mathrm{li-}$ bro de cuentas atrasadas (p. 8).

\section{Reflexiones finales}

Para los optimistas, la Reforma Universitaria constituyó un paso fundamental en la democratización de las clases medias y populares latinoamericanas, que venía a colación de un proceso mayor de ampliación progresiva de derechos. Esta es la postura que defendieron pensadores como Gabriel del Mazo, vinculado a la tradición radical. ${ }^{64}$ Para los apocalípticos y pesimistas, como Maximio Victoria, la subversión de las jerarquías pedagógicas al interior de los claustros universitarios era un síntoma más de un clima de época signado por la degradación moral, la violencia contra el orden y el libertinaje. Otras voces, consideraron que

62. La intervención de la facultad (12 de febrero de 1931). ED, p. 1.

63. Sobre la estabilidad de la Facultad de Ciencias Económicas y Educacionales (5 de marzo de 1931). ED, p. 1.

64. Para las interpretaciones en disputa, véase: Bustelo (2018). 
la Reforma Universitaria sólo tendió a retrasar un proceso revolucionario en ciernes, llegando a reforzar las hegemonías de la elite, que prontamente (a partir de 1923) supo reconquistar espacios dentro de la Universidad con su acción reaccionaria (Portantiero, 1987).

La avanzada comunista en Europa y la crisis de posguerra, junto al aumento de la conflictividad obrera desde 1919 y las disputas dentro del partido gobernante, hicieron que poco a poco algunos radicales confluyeran con la mirada de los conservadores. El peligro de la revolución era inminente siendo necesario extirparlo de raíz; y los estudiantes eran parte de ese complot maximalista en ciernes. Para 1931 la opinión de muchos que promovieron la "jerarquización" universitaria, había cambiado radicalmente:

La reforma universitaria es una de esas conquistas y si ha fracasado es más que por su justicia, por el uso que de ella se ha hecho. Así suele fracasar también la libertad, cuando se hace un abuso de la misma. Hasta que el alumnado sepa manejar los derechos sin perjudicar los intereses de la cultura pública, y hasta que los profesores sepan llevar la dignidad de sus cargos sin sometimientos a otros intereses ajenos a la enseñanza, la medida restrictiva que proyecta decretar el gobierno, puede ser saludable para las universidades argentinas. ${ }^{65}$

El caso entrerriano es representativo en ese sentido y no escapa de los avatares del reformismo en el resto de las sedes de la Universidad del Litoral, ya que de forma temprana muestra las tensiones de un movimiento que nació con una fuerza irrefrenable en 1918 pero que en la década del veinte se diluyó en una

65. La reforma de los estatutos universitarios (2 de abril de 1931). ED, pp. 3-4.

102 creciente apatía y desencanto ante los vientos maximalistas.

Este estado de situación, para la década del treinta, favorece a los sectores dentro de la universidad que propiciaban una lectura más conservadora de la reforma. La experiencia truncada de la Facultad de Ciencias Económicas y Educacionales de Paraná, es un ejemplo elocuente.

En síntesis, la Reforma Universitaria, que en sus comienzos fue abrazada por los normalistas porque venía a "jerarquizar" a la antigua Escuela Normal, con el transcurrir del tiempo, demostró que iba a contrapelo de sus aspiraciones. Poco a poco, la facultad comenzó a ser percibida como un espacio de degradación moral y decadencia política, producto de la circulación de ideas en boga durante la década del veinte.

Para Victoria, este proceso representó un punto de inflexión. Como positivista confeso, experimentó uno de los mayores miedos de ese pensamiento: la "rebelión de las masas" contra el orden; en este caso, de estudiantes contra la autoridad docente. Como católico, sintió irritación contra el laicismo "sovietista" imperante de los nuevos tiempos. ${ }^{66} \mathrm{Y}$ como normalista, vio sepultarse en el pasado a la institución que lo había formado y que él había dirigido.

66. Si bien Victoria no tenía lazos importantes con la institución católica de la provincia de Entre Ríos nunca renegó de su identidad católica y en sus memorias aparecía con fuerza sus posicionamientos en defensa de la religión. Su actitud ante el proceso reformista no era excepcional y se ajusta a lo que Diego Mauro (2018) ha explorado para otros contextos. La confusión del momento maximalista y el tiempo del reformismo universitario hizo que muchos católicos, expectantes al principio, no dudaron en condenar las transformaciones. 
Su figura fue la puerta de entrada para dar cuenta de los avatares de la experiencia reformista, por fuera de las grandes ciudades. Seguramente este actor, no es un reflejo de la totalidad del espectro crítico a los caminos seguidos por el reformismo universitario, pero sí muestra cómo en un espacio provincial, la Reforma concitó reacciones adversas que llevaron al truncamiento de su primera facultad.

$\propto \tilde{\bullet} \propto$

Recibido: 12-11-2018

Aceptado: 29-04-2019

Publicado: 04-06-2019 


\section{Referencias Bibliográficas}

Agüero, A. C. (2018). La Reforma Universitaria y la política al ras del suelo. Corpus, 8(1), 1-7. Recuperado de https://journals.openedition.org/corpusarchivos/2226\#quotation

Altamirano, C., Sarlo, B. (1983). Ensayos argentinos. De Sarmiento a la vanguardia. Buenos Aires: Centro Editor de América Latina.

Bacolla N. (2018). Reformismo, elites y "cuestión universitaria": la creación de la Universidad Nacional del Litoral. En I. Martínez y N. Bacolla (Coords.), Universidad, élites y política. De las reformas borbónicas al reformismo de 1918 (pp. 231-264). Rosario: HyA ediciones.

Bertero, E., Pini, V., Vicentín, M. (2015). Logia Armonía. Masones y librepensadores en la esfera pública: Santa $\mathrm{Fe}, 1889-1921$. Santa Fe: Ediciones UNL.

Buchbinder, P. (2005). Historia de las Universidades Argentinas. Buenos Aires: Sudamericana.

Buchbinder, P. (2006). De la impugnación al profesionalismo a la crítica de la Reforma: perspectivas de la Universidad. En D. Roldán (Comp.), Crear la democracia (pp. 237-268). Buenos Aires: Fondo de Cultura Económica.

Buchbinder, P. (2008). ¿̇Revolución en los claustros? La Reforma Universitaria de 1918. Buenos Aires: Sudamericana.

Burrow, J. (2001). La crisis de la razón. El pensamiento político europeo 1848-1914. Barcelona: Crítica.

Bustelo, N. (2015). La reforma universitaria desde sus grupos y revistas: Una reconstrucción de los proyectos y las disputas del movimiento estudiantil porteño de las primeras décadas del siglo XX (1914-1928) (Tesis doctoral). Universidad Nacional de La Plata, La Plata, Argentina. Recuperado de http://www.memoria. fahce.unlp.edu.ar/tesis/te.1307/te.1307.pdf

Bustelo, N. (2018). Los estudiantes que trascienden las aulas. Gabriel del Mazo y las fuentes documentales de la Reforma Universitaria. En A. Agüero, A. Eujanian (Coords.), Variaciones del reformismo. Tiempos y experiencias (pp. 139-166), Rosario: HyA ediciones.

Camarero, H. (2017). Tiempos Rojos. El impacto de la Revolución Rusa en Argentina. Buenos Aires: Sudamericana.

Carli, S. (1995). Entre Ríos. Escenario Educativo 1883-1930. Paraná: Editorial de la Universidad de Entre Ríos.

Carli, S. (2001). Modernidad, diversidad cultural y democracia en la historia educativa entrerriana (18831930). En A. Puiggrós (Dir.), La Educación en las Provincias y Territorios Nacionales (1885-1945) (pp. 185-23). Buenos Aires: Galerna.

Carrizo, B. (2009). Temas y debates en tiempos de cambio. La legislatura de Santa Fe, 1912-1916. Ponencia presentada en XIIJornadas Interescuelas/Departamentos de Historia. Departamento de Historia. San Carlos 
de Bariloche, Argentina: Universidad Nacional del Comahue. Recuperado de http://cdsa.aacademica. org/000-008/122.pdf

Chaunu, P. (1983). Historia y decadencia. Barcelona: Juan Granica.

Ciria, A., Sanguinetti, H. (2006). La Reforma Universitaria (1918-2006). Santa Fe: Ediciones UNL.

Culó, J. (1949). Maximio Victoria. Un apóstol del normalismo. Su concepto de Educación. Tellvs, 13-14.

Echeverría, O. (2009). Las voces del miedo. Los intelectuales autoritarios argentinos en las primeras décadas del siglo $X X$. Rosario: Prohistoria.

Figueroa, S. (1934). Escuela Normal de Paraná. Datos Históricos 1871-1895. Paraná: Predassi impresores.

Fiorucci F. (2014). Maestros para el sistema de educación pública. La fundación de escuelas normales en Argentina (1890-1930). Revista Mexicana de Historia de la Educación, 2(3), 25-45. Recuperado de https://ri.conicet.gov.ar/bitstream/handle/11336/35527/CONICET_Digital_Nro.08b2aae6-1c724ef2-9c32-1a0596fb631b_A.pdf?sequence=2\&isAllowed $=y$

Herrero, A. (2014). La escuela normal y la voluntad científica de los nuevos educadores (Argentina, 18801900). Revista Perspectivas Metodológicas, 14(14), Universidad Nacional de Lanús. Recuperado de http:// revistas.unla.edu.ar/epistemologia/article/view/420/436

Herman, A. (1998). La idea de decadencia en la historia occidental. Santiago de Chile/Barcelona: Editorial Andrés Bello.

Kummer, V; Olalla, V; Baffico F; López P. (2010). La Facultad de Ciencias Económicas y Educacionales. En E. Ossanna y P. López (Dirs.). Historia de la Facultad de Ciencias de la Educación de Paraná 1920-1973. (pp. 75-118) Paraná: EDUNER.

Kummer, V. (2011). José Maria Torres: las huellas del pensamiento en la conformación del campo pedagógico normalista. Paraná: EDUNER.

Koselleck, R. (2012). Historias de conceptos. Estudios sobre semántica y pragmática del lenguaje politico y social. Madrid: Editorial Trotta.

Lionetti, L. (2005). La función republicana de la escuela pública: la formación del ciudadano en Argentina a fines del siglo XIX. Revista Mexicana de Investigación Educativa, 10(27), 1225-1259. Recuperado de: http://historiapolitica.com/datos/biblioteca/lionetti.pdf

Lvovich, D. (2003). Nacionalismo y antisemitismo en la Argentina. Buenos Aires: Javier Vergara Editor.

Mauro, D. (2008). Católicos en la prensa profana. Nueva Época frente al reformismo liberal. Santa Fe 1920-1923. Revista Andes, (19), Salta, 93-117. Recuperado de http://www.scielo.org.ar/pdf/andes/n19/ n19a04.pdf

Mauro, D. (2018). Los católicos frente a la reforma universitaria (1917-1922). En D. Mauro, J. Zanca 
(Coords.). La reforma universitaria cuestionada. Rosario: HyA ediciones.

McGee Deutsch, S. (2003). Contrarevolución en la Argentina, 1900-1932: la Liga Patriótica Argentina. Bernal: Universidad Nacional de Quilmes.

Moyano, J. (2017). Los estudiantes reformistas cordobeses en 1918. Clivajes, aliados y antagonistas, Integración y conocimiento, 6(1), 53-65. Recuperado de https://revistas.unc.edu.ar/index.php/ integracionyconocimiento/article/view/17118

Ossanna, E y López, P. (Dirs.). (2010). Historia de la Facultad de Ciencias de la Educación de Paraná 19201973. Paraná: EDUNER.

Pereira, E. (2012). Diccionario biográfico nacional. Unión Cívica Radical. Buenos Aires: Ediciones IML.

Piazzesi, S., Bacolla, N. (2015). El reformismo entre dos siglos. Historias de la UNL. Santa Fe: Ediciones UNL.

Portantiero, J. C. (1987). Estudiantes y Politica en América Latina. El proceso de la Reforma Universitaria 19181938. Buenos Aires: Siglo XXI.

Puiggrós, A. (Dir.) (2001). Historia de la Educación en la Argentina IV: La Educación en las Provincias y Territorios Nacionales (1885-1945).Buenos Aires: Galerna.

Reula, F. (1969). Historia de Entre Ríos 3. Santa Fe: Castellví.

Rubinzal, M. (2017). Contra la revolución. Circulación cultural y discursos decadentistas en la Argentina (1917-1922). Prismas. Revista de historia intelectual, (21), 241-246. Recuperado de http://www.unq.edu. ar/advf/documentos/5a3ab1face4e6.pdf

Saítta, S. (2013). Regueros de tinta. El diario Crítica en la década de 1920. Buenos Aires: Siglo XXI editores.

Salvadores A. (1966). Historia de la Instrucción Pública en Entre Ríos. Paraná: Ediciones Museo Histórico de Entre Ríos.

Svampa, M. (1994). El dilema argentino. Civilización o Barbarie. Buenos Aires: Taurus.

Schmit, R. (2015). Caudillos, politica e instituciones en los orígenes de la nación argentina. Buenos Aires: Ediciones UNGS.

Tato, M. I. (2004). Viento de Fronda. Liberalismo, Conservadurismo y Democracia en la Argentina 1911-1932. Buenos Aires: Siglo XXI.

Tedesco, JC. (1986). Educación y sociedad en Argentina (1880-1945). Buenos Aires: Ediciones Solar.

Terán, O. (2008). Historia de las ideas en la Argentina. Diez lecciones iniciales, 1810-1980. Buenos Aires: Siglo XXI.

Vásquez, A. (1970). Periódicos y periodistas en Entre Ríos. Paraná: Imprenta de Entre Ríos. 
Victoria, M. (1910). La Escuela Normal del Paraná en 1910. Informe Anual. Buenos Aires: Compañía Sudamericana de Billetes de Banco.

Victoria, M. (1912a). El gobierno de las Escuelas Normales. En Archivos de pedagogía y ciencias afines. Buenos Aires: Talleres de la Casa Jacobo Peuser, 1906-1914.

Victoria, M. (1912b). Orientaciones de la Educación Argentina. En Archivos de pedagogía y ciencias afines 19061914. Buenos Aires: Talleres de la Casa Jacobo Peuser.

Victoria, M. (1922a). Pedagogía Social. Revista Universitaria del Litoral, (3), 133-145.

Victoria, M. (1922b). La desintegración de la Cultura. El socialismo y la Educación. Revista Universitaria del Litoral, (4), 37-58.

Victoria, M. (1936). Los Orígenes del Catolicismo y de la Eucaristía. Buenos Aires: Biblioteca Racionalista Francisco Bilbao.

Zanini, A. (1926). Páginas de oro de la ciudad de Paraná: en su primer centenario. 1826-1926. Buenos Aires: Caracciolo y Plantié.

Zimmerman, E. (1994). Los liberales reformistas. La cuestión social en Argentina 1890-1916. Buenos Aires: Sudamericana. 